\title{
Perfectionism and community-identity integration: the mediating role of shame, guilt and self-esteem
}

\author{
Konrad Piotrowski ${ }^{1}$ (D) $\cdot$ Agnieszka Bojanowska $^{2} \cdot$ Aleksandra Nowicka $^{3} \cdot$ Bartosz Janasek $^{3}$
}

Accepted: 11 February 2021 / Published online: 1 March 2021

(C) The Author(s) 2021

\begin{abstract}
Recent years have been marked by a rise in perfectionism in developed countries. Studies have shown that dimensions of perfectionism are related to the way people handle identity crises, whose successful resolution leads to finding a place within the adult community. In the present study, we aimed to show that two dimensions of perfectionism - perfectionistic strivings and perfectionistic concerns - are related to the outcomes of identity formation and that these relationships are mediated by shame and guilt-proneness, and self-esteem. A path mediation model showed that shame and self-esteem fully mediate the relationship between two dimensions of perfectionism and community-identity. These findings have both theoretical and practical implications. Firstly, they show the mechanism by which perfectionism may be related to identity stage resolution. Secondly, our results support the distinction between perfectionistic strivings expressing drive towards excellence, and perfectionistic concerns expressing fear of failure and fear of being judged in identity studies. This in turn may contribute to more fitting and nuanced psychotherapeutic interventions, as it justifies the application of psychotherapeutic tools aimed at reducing perfectionistic concerns and enhancing perfectionistic strivings.
\end{abstract}

Keywords Identity $\cdot$ Identity crisis $\cdot$ Perfectionism $\cdot$ Shame $\cdot$ Guilt $\cdot$ Self-esteem

\section{Introduction}

From adolescence to late adulthood, one of the key developmental challenges people face is to establish and maintain a relatively stable sense of identity. Identity allows people to perceive themselves as one and the same person, regardless of the context, and to experience self-continuity (Erikson, 1950). With successful resolution of an identity stage, a person becomes less susceptible to external pressures and gains an increased awareness of his or her needs, which in turn translates into an enhanced sense of independence and individuality and increased quality of life (Marcia, 1980). Importantly, in recent decades the process of identity formation has become increasingly difficult. In the modern world,

Konrad Piotrowski

konrad.piotrowski@swps.edu.pl; https://www.researchgate.net/ profile/Konrad_Piotrowski

1 Centre for Research on Personality Development, SWPS University, Poznań, Poland

2 Psychology Institute, SWPS University, Warsaw, Poland

3 Faculty of Psychology and Law, SWPS University, Poznań, Poland people face many barriers, very high expectations and are required to find their life paths and cope with various obstacles using their own, personal resources (Côté, 2006, 2016). Another noticeable change in modern societies observed during the last 30 years is an increase in perfectionism (Curran \& Hill, 2019). As Curran and Hill (2019) speculate, this increase in perfectionism results from an increase in individualism, materialism, social antagonism, and competitiveness in Western societies and changes in parenting practices that have become more controlling and anxiety-driven. As dozens of studies proved that perfectionism profoundly impacts behavior, emotional and cognitive functioning, and enhances the risk of psychopathology (Stoeber \& Otto, 2006), we can assume that it also changes how people cope with identity formation. Surprisingly, studies on the relationships between perfectionism and identity formation are scarce, and only some of them focused on the potential mechanism of influence of perfectionism on identity. The present study aimed to fill this gap by analysing links between trait perfectionism, a sense of identity and identifying characteristics that could mediate this relationship. As the steep increase in perfectionism is one of the sources of current mental illness epidemics (Curran \& Hill, 2019) and identity disturbances are also seen as making individuals vulnerable to psychopathology (Klimstra \& Denissen, 
2017), the knowledge about the associations between perfectionism and a sense of identity is of the utmost importance for understanding the existential and mental health difficulties experienced by many people in modern societies.

\section{Perfectionistic Strivings, Perfectionistic Concerns and Psychological Adjustment}

Perfectionism is a personality trait that is expressed in setting extremely high, at times unrealistic expectations for oneself and having a strong will to carry them out flawlessly; this tendency is often accompanied by fear of being judged and uncertainty about one's competences (Hewitt \& Flett, 1991, Frost et al., 1990). The primary sources of perfectionism development in an individual are harsh and demanding parenting experienced in childhood and adolescence, and social and cultural pressure to be perfect experienced during socialization (Morris \& Lomax, 2014). Various expressions of perfectionism can be grouped into two higher order dimensions (Stoeber \& Otto, 2006): (1) perfectionistic strivings, i.e. having very high expectations and being driven to carry them out; (2) perfectionistic concerns, i.e. defined as fear of failure, strong self-criticism, excessive sensitivity to external criticism. Although these two dimensions are positively correlated (striving for perfection is often accompanied by high concern), their impacts on people's functioning are different. When shared variance of these two dimensions is being controlled for, perfectionistic strivings correlate with higher selfacceptance, motivation, self-efficacy, task-oriented coping and high quality of life (Ashby et al., 2006; Stoeber \& Otto, 2006; Eum \& Rice, 2011), while perfectionistic concerns correlate with higher negative affect, depression, stress and dysfunctional coping styles (Dimaggio et al., 2015; Castro et al., 2017; Malivoire et al., 2019). Additionally, each of these dimensions has unique relationships with basic personality traits. Perfectionistic strivings correlate positively with conscientiousness, whereas perfectionistic concerns with neuroticism (Ulu \& Tezer, 2010; Stoeber et al., 2018). Moreover, perfectionism, especially perfectionistic concerns play a significant role in the development of mental disorders, such as depression, anxiety, eating, obsessive-compulsive and somatic disorders (Enns et al., 2002; Reuther et al., 2013; Sirois \& Molnar, 2014; Slof-Op’t et al., 2016).

Studies carried out so far show, however, that perfectionism impacts adaptation mainly indirectly, through cognitive and emotional functioning (Flett et al., 2002). Negative cognitive consequences of perfectionism, related mainly to the level of perfectionistic concerns, include high indecisiveness, high rumination and black and white thinking, while emotional consequences include the tendency to experience anxiety, proneness to guilt (a self-conscious emotion that arises when an individual assesses his/her specific behaviour as not fulfilling personal standards; Orth et al., 2006), shame (a self- conscious emotion that results from a negative evaluation of the whole self in a situation of not fulfilling personal standards; Orth et al., 2006), and low self-esteem. According to Flett et al. (2016), this specific cognitive and emotional functioning of perfectionists translates into higher and prolonged experience of stress, which in turn leads to psychopathology and somatic health issues. In the present study, we focused specifically on whether emotional and cognitive factors related to perfectionism may also lead to poorer outcomes of identity formation processes in adulthood.

\section{Perfectionism and Identity Formation}

The first systematic attempt at explaining the relationship between perfectionism and identity development were carried out by Luyckx and colleagues (Luyckx, Soenens, et al., 2008), who conducted studies among high-school students and college freshmen. Their two studies showed, that perfectionistic strivings are positively correlated with dealing with identity crises. Contrastingly, perfectionistic concerns, were positively related to difficulties with identity formation. These observations demonstrate how complex the relationship between perfectionism and identity actually is. Perfectionistic strivings (pursuit of perfection) alone seem to help people to answer various identity questions, but if they are accompanied by perfectionistic concerns (fears, doubts, and concerns related to failure and underachievement), then perfectionism may lead to difficulties with identity formation and a prolonged state of identity diffusion. The authors conclude (Luyckx, Soenens et al., 2008) that perfectionistic concerns lead to constant concentration on the unmet (often unrealistic) internal standards. Therefore, instead of engaging in proactive explorative activities or commitment making, high-concern perfectionists (called maladaptive perfectionists; Stoeber \& Otto, 2006) seem to be stuck in a closed circle of rumination. Consequently, perfectionistic concerns disrupt selfactualization processes and hamper the development of a more consolidated, realistic and integrated set of identity commitments (Luyckx, Soenens et al., 2008). Results presented by Luyckx have been confirmed by Piotrowski (2019) in a Polish sample of young adults. Additionally, Piotrowski observed that perfectionistic concerns have a negative, indirect impact on the formation of identity, because people high in this aspect of perfectionism tend to experience shame and guilt often, they worry a lot and have difficulties in making decisions. Whereas the studies conducted by Luyckx, Soenens and colleagues (2008), and by Piotrowski (2019) focused on the identity domain of the vision of one's future, newer studies conducted by Piotrowski (2020) showed that perfectionism can also hamper the development of parental identity.

The study conducted by Piotrowski (2019) is so far the only attempt at identifying the mediators of the relationship between perfectionism trait and sense of identity. 
Furthermore, hitherto studies on the relationship between perfectionism and identity (Luyckx, Soenens et al., 2008; Piotrowski, 2019; Piotrowski, 2020) focused exclusively on two processual models formulated in the Marcian tradition: Luyckx's model (Luyckx, Schwartz et al., 2008) and MeeusCrocetti's model (Crocetti et al., 2008), so naturally they concentrated on detailed, domain-specific processes of exploration (looking for information about identity options) and commitment (making important, identity-relevant decisions) and did not address other aspects of identity. We aim to fill this gap in the present article by focusing on the identity capital model proposed by Côté $(1996,2016)$. This model has not previously been used in studies on the perfectionism-identity link and it provides a general, non-domain specific perspective on identity that has not been present in earlier studies. Compared to the models developed by Luyckx et al. (2008) and Meeus and Crocetti (2008) represented in past studies on perfectionism and identity (Luyckx, Soenens, et al., 2008; Piotrowski, 2019, Piotrowski, 2020), the identity capital model tends to emphasize the final aims of identity formation, rather than an underlying, basic processes and their dynamic.

In line with the identity capital model, we conceptualized the resolution of identity stage in terms of community-identity integration. This integration is rooted in a subjective perception that a stage of life associated with looking for a life path has ended and that an individual has found his/her own place in the world, a social niche and a group of people, with whom they wish to spend their life. In line with other studies on identity development, high community-identity integration proved to be related to higher adaptation and well-being and lower psychopathology symptoms (Côté, 2016), making the level of community-identity integration a good indicator of identity synthesis (Marcia, 1980).

According to Côté (2016), identity stage resolution is profoundly influenced by several agentic traits, such as self-esteem, ego strength, locus of control, critical thinking, moral and cognitive reasoning. These traits are seen as capacities: they help people understand and deal with obstacles and opportunities encountered on the path to adulthood and to a stable and well-established identity (Côté, 2016). From this perspective, perfectionism needs to be divided into two categories: adaptive and maladaptive. Adaptive perfectionism, expressed in high strivings and low concerns (Luyckx, Soenens, et al., 2008; Piotrowski, 2019; Stoeber $\&$ Otto, 2006), would help in identity formation through a set of well-developed agentic traits correlated with perfectionistic strivings (e.g. high self-esteem, positive emotionality, internal locus of control); whereas maladaptive perfectionism, expressed in high strivings and high concerns would be a great hindrance in dealing with challenges that people meet when forming an identity in the modern world, mostly because high concerns are associated with a number of psychological difficulties including depression and other mental issues (Stoeber \& Otto, 2006). This topic has not previously been studied within the identity capital approach and in the present research we decided to focus on the role of different facets of perfectionism in acquiring a sense of community-identity integration in adulthood. We were also interested in identifying the cognitive and emotional mediators of this relationship as perfectionism mostly has an indirect impact on adaptation. We believe that our study could not only help develop the identity capital model further, but it can also elucidate the processes of identity formation in the current, perfection-driven times.

\section{Research Questions and Hypotheses}

Firstly, we aimed to investigate how perfectionistic strivings and concerns are related to the sense of community-identity integration. We expected results similar to those presented by Luyckx, Soenens and colleagues (2008) and by Piotrowski $(2019,2020)$, i.e. that perfectionistic strivings would correlate positively with community-identity integration, whereas perfectionistic concerns would be related negatively to this aspect of identity.

Secondly, we looked for mediators of this relationship. Basing on the study conducted by Piotrowski (2019) and on studies on the mediators between perfectionism and depressive symptoms (Ashby et al., 2006), we expected that higher levels of perfectionistic concerns would be related to a more frequent experience of shame, guilt and lower self-esteem and that these dimensions would directly predict a sense of identity. We also expected, that perfectionistic strivings would not be related (Ashby et al., 2006) or would be related negatively (Piotrowski, 2019) to shame and guilt proneness and positively to self-esteem. The latter effect would prove that perfectionistic strivings either help develop agentic traits or are a part of them.

\section{Materials and Methods}

\section{Participants}

Data were collected among a sample of 158 individuals, aged 20-50 $(M=30.78, S D=5.75, M e=32), 117$ of which were women $(74.1 \%)$. At the time of the study all participants were full-time or part-time students of psychology. Seventy-nine percent of them had a prior degree.

\section{Measures}

Perfectionism. The assessment of perfectionistic strivings and perfectionistic concerns was carried out with the use of Frost Multidimensional Perfectionism Scale (FMPS; Frost et al., 1990) in the Polish adaptation by Piotrowski and 
Bojanowska (2019). The scale consists of 35 items, which form 6 subscales. In the present study we used 3 of them: Personal Standards ( 7 items, e.g. It is important to me that I be thoroughly competent in everything I do), that constitute an index of perfectionistic strivings; Concern over mistakes (9 items, e.g. If I fail at work/school, I am a failure as a person) and Doubts about actions (4 items, e.g. Even when I do something very carefully, I often feel that it is not quite done right) that jointly constitute an index of perfectionistic concerns. The remaining three subscales have been criticized for their low theoretical validity (Stoeber \& Otto, 2006; Piotrowski \& Bojanowska, 2019), so they were excluded from the study. Participants rated the statements on a 5 point scale from 1Strongly disagree, to 5-Strongly agree. Cronbach's alpha for the perfectionistic strivings was .76, and for the perfectionistic concerns it was .88 .

Community-identity integration was measured with one of the scales of the Identity Stage Resolution Index (ISRI; Côté, 1997; Polish adaptation: Piotrowski \& Brzezińska, 2015), i.e. Community Identity Resolution Scale (CIRS). This subscale assesses a general sense of identity stage resolution with 3 items: You have found your "niche" in life; You have settled on a lifestyle that you are satisfied with for the remainder of your life; You have found a "community" in which to live for the remainder of your life. Respondents indicate their answers on a scale from 0-Not at all true, to 4-Entirely true. Cronbach's alpha was .86. The ISRI also includes a subscale of adult identity, but it has not been used in this study because with the varying age of the participants, the validity of the scale could be questioned.

Shame and guilt proneness were measured with the Personal Feelings Questionnaire - 2, PFQ-2; Harder \& Zalma, 1990) adapted to Polish by Piotrowski (Piotrowski \& Brzezińska, 2017). The scale consists of 22 adjectives describing various emotional states, 10 of which refer to shame (e.g. feeling humiliated, embarrassed), and 6 refer to guilt (e.g. feeling guilt, remorse). The remaining items serve as a buffer and they are not included in the calculations of shame and guilt indices. Participants rated the items on a 5 point scale, from 0-never to 4-continuously or almost continuously. Cronbach's alpha was .82 for shame and .84 for guilt.

Self-esteem was assessed with the Rosenberg Self-Esteem Scale (RSES; Rosenberg, 1965; Laguna et al., 2007), which is designed to measure explicit self-esteem. It consists of 10 items (e.g. On the whole, I am satisfied with myself), assessed on a 4 point scale from 1-totally disagree, to 4-totally agree. Cronbach's alpha was .89 .

\section{Procedures}

The study was conducted among psychology students, who are required to participate in scientific research as part of their curriculum. They received ECTS points for their participation.
We provided information on the aim of the study, assured the participants that their participation was voluntary and asked them to provide written consent.

\section{Analytical Strategy}

First, we analysed missing data (less than $0.5 \%$ of the entries) assuming that data were missing completely at random (MCAR test insignificant). No modifications to the dataset were performed. Next, we calculated correlation coefficients with the use of the SPSS 26, and then conducted a path analysis in Mplus 7.3 (Muthén \& Muthén, 1998-2012) according to a procedure suggested by Holmbeck (1997): direct effects model A was tested first in order to assess the relationships between each of the predictors (perfectionistic strivings and perfectionistic concerns) and community-identity (at this stage the mediators were not included); full mediation Model B was used to verify if shame, guilt and self-esteem mediated the relationship between perfectionism and identity (no direct relationship between perfectionism and identity was assumed in the model); partial mediation Model $\mathrm{C}$ assumed that there would be direct (perfectionism-identity) and indirect effects. Model fit was assessed with three common indices $(\mathrm{Hu} \&$ Bentler, 1999): the Comparative Fit Index (CFI), whose value over .95 indicates good fit; the Root Mean Square Error of Approximation (RMSEA), whose value should be below .06; and the Standardized Root Mean Square Residual (SRMR), whose value below .08 indicates good fit. A, B and C models were then compared in terms of the changes in fit indices (Chen, 2007): changes are interpreted as significant when $\Delta \mathrm{CFI} \geq 0.010, \Delta \mathrm{RMSEA} \geq 0.015, \Delta \mathrm{SRMR} \geq 0.010$. We also used Akaike's Information Criterion (AIC) for each of the models. Differences above 10 points are interpreted as significant (Burnham \& Anderson, 2004). Because the multivariate distribution of the models was significantly different from normality, we used the Satorra-Bentler scaled $X^{2}$ (SBS- $X^{2}$; Satorra and Bentler, 1994) in the estimation of model parameters.

\section{Results}

\section{Descriptive Statistics and Correlation Analysis}

Table 1 presents descriptive statistics and correlations between the variables. Two dimensions of perfectionism turned out to be moderately, positively correlated with one another, suggesting that they are relatively independent. Contrastingly, shame and guilt were strongly correlated with one another. Perfectionistic concerns were positively and moderately correlated with shame and guilt, and negatively with self-esteem and community-identity. Perfectionistic strivings, however, did not correlate with neither the mediators nor with identity. 
Table 1 Descriptive statistics and correlations

\begin{tabular}{|c|c|c|c|c|c|c|c|c|c|}
\hline & Range & $M$ & $S D$ & 1 & 2 & 3 & 4 & 5 & 6 \\
\hline 1. Perfectionistic strivings & $10-33$ & 23.39 & 4.90 & - & & & & & \\
\hline 2. Perfectionistic concerns & $14-58$ & 32.57 & 9.91 & $.42 * *$ & - & & & & \\
\hline 3. Shame & $1-33$ & 14.83 & 5.97 & -.02 & $.58 * * *$ & - & & & \\
\hline 4. Guilt & $1-21$ & 9.68 & 4.15 & .01 & $.42 * * *$ & $.62 * * *$ & - & & \\
\hline 5. Self-esteem & $12-40$ & 29.95 & 6.20 & -.05 & $-.45 * * *$ & $-.49 * * *$ & $-.38 * * *$ & - & \\
\hline 6. Community-identity & $0-12$ & 7.85 & 2.92 & .07 & $-.35 * * *$ & $-.47 * * *$ & $-.28 * * *$ & $.51 * * *$ & - \\
\hline
\end{tabular}

$* * * * * * p<.05 ; p<.01 ; p<.001$

Shame and guilt correlated negatively with self-esteem and community-identity.

Earlier research suggested that the study variables would be connected to age and gender (Piotrowski, 2019), so we conducted additional analyses. However, it turned out that age was not significantly correlated to any of the study variables, whereas the only significant difference between men and women was found for shame (higher among women; $p<.05$ ). The impact of these two variables was therefore controlled for (included as predictors) in all path models. Despite the lack of significant correlations between age and the other study variables, we decided to control for age in the path models, as it weakly correlated with community-identity integration $(r=.13, n s)$ and we wanted to be certain that it would not influence the relationships between other variables.

\section{Mediation Analysis}

Despite the lack of correlation between perfectionistic strivings and community-identity (Table 1), this variable was included in model A, because it often plays a role in a suppression effect which cannot be observed in a bi-variate correlation analysis (the positive impact of strivings is only observed after controlling for perfectionistic concerns; Stoeber \& Damian, 2016).

Model A had no degrees of freedom and fit the data perfectly. Perfectionistic strivings were positively $(\beta=.25$, $p<.01$, while perfectionistic concerns were negatively correlated with community-identity $(\beta=-.44, p<.001)$. Both of these perfectionism dimensions explained $18 \%$ of the dependent variable variance. As expected, perfectionistic strivings were subject to suppression effect, i.e. we found a stronger relationship between perfectionistic strivings and community-identity in the path model, compared to bivariate correlations.

Model B (full mediation model) fit the data very well, with SBS- $X^{2}(2, N=158)=1.84, p>.05, \mathrm{CFI}=1.00$, RMSEA $<.001, \mathrm{SRMR}=.012, \mathrm{AIC}=6779.52$. Perfectionistic strivings turned out to be negatively related to both shame and guilt, and unrelated to self-esteem, whereas perfectionistic concerns were positively related to shame and guilt, and negatively to self-esteem. Among the mediators, shame was negatively $(-.32, p<.05)$, while self-esteem was positively $(.37$, $p<.001)$ correlated with community-identity integration. Guilt did not correlate with community-identity (.05, $p>.05)$. Model B explained 33\% of the variance in the dependent variable.

Finally, we tested partial mediation, Model C, where we tested direct and indirect (via mediators) relationships between perfectionism and identity. Since guilt in Model B turned out not to be correlated with identity, this path was set to zero, so that goodness of fit parameters could be estimated. Model C fit the data well, with SBS- $X^{2}(1, N=158)=.0 .39, p>.05$, $\mathrm{CFI}=1.00, \mathrm{RMSEA}<.001, \mathrm{SRMR}=.001, \mathrm{AIC}=6779.49$. It explained $34 \%$ of the variance in the dependent variable. Changes in model fit parameters suggested that model $\mathrm{C}$ did not explain the relationships between the variables better than model B: $\triangle \mathrm{CFI}<.001, \triangle \mathrm{RMSEA}<.001, \triangle \mathrm{SRMR}=0.011$, $\Delta \mathrm{AIC}=0.03$. Additionally, direct relationships between perfectionistic concerns and strivings with community-identity in Model $\mathrm{C}$ did not reach the level of significance. These results showed that Model B best described the relationships between the variables (Fig. 1).

\section{Discussion}

A rise in perfectionism in Western societies in the recent decades suggests that as competitive and individualistic societies evolve, they tend to put more pressure on people and expect them to pursue often unachievable goals (Curran \& Hill, 2016). Developing a stable and satisfying identity in such a context may be difficult, especially when an individual is anxious not to make mistakes and fears criticism. In the present study, we aimed to elucidate the relationships between perfectionism in adults and their identity-community integration, which is one of the indicators of identity stage resolution according to the identity capital model (Côté, 1997). We also aimed to identify significant cognitive-emotional mechanisms that could explain the perfectionism-identity link. 
Fig. 1 Path model B presenting relationships between the variables. Note: all presented path coefficients reached at least the level of significance at $p<.05$; for the sake of clarity, relationships with the controlled variables are not presented: gender and shame $\beta=-.17$

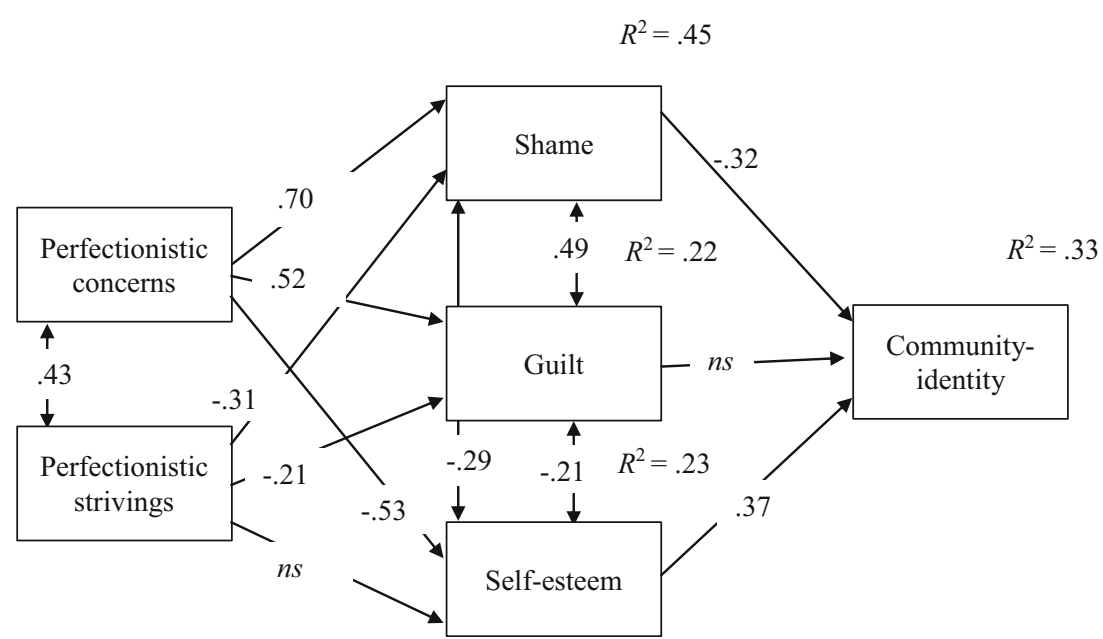

The obtained results are consistent with earlier findings (Luyckx, Soenens et al., 2008, Piotrowski, 2019), which showed that perfectionistic strivings, a core aspect of perfectionism, are in fact adaptive characteristics that foster identity formation. On a more general level, not limited to specific domains of identity, our results show, that people who pursue flawlessness and who hold extremely high standards, are more likely to cope with identity issues successfully. For this reason, we suggest that perfectionistic strivings, whose positive impact on everyday functioning is well-founded, be seen as another important part of agentic personality stressed in the identity capital model (Côté, 2016). Perfectionistic strivings, however, are often (but not always) accompanied by perfectionistic concerns whose links with identity formation difficulties were observed in the studies conducted by Luyckx, Soenens and colleagues (2008), by Piotrowski (2019), and also in the research presented here. Importantly, the negative impact of concerns is usually stronger than the positive impact of strivings (Stoeber \& Damian, 2016), which was also confirmed in our sample. As a result, we can expect that the impact of perfectionism on identity development depends on each person's specific levels of perfectionistic strivings and concerns. The stronger perfectionistic concerns, the more difficulties are to be expected. Consequently, for people whose perfectionism consists of high strivings and low concerns, it is a resource that helps deal with challenges and obstacles in identity formation. For others, whose perfectionism consists of high strivings and high concerns, it may be a risk factor leading to identity disturbances. The present study also suggests which mechanisms may be responsible for such relationships. Perfectionistic strivings are associated with less frequent experience of shame, a very difficult emotion that makes people question the value of their whole self (Lewis, 2008). As it turned out, shame mediates the perfectionistic strivings-identity link. Strong perfectionistic strivings motivate people to achieve their goals and therefore they can facilitate positive emotions leading to a conclusion that one is doing well and that they are in the right place in their life. This configuration, however, changes when the strivings are accompanied by a strong fear of being judged, of failure and being ridiculed (perfectionistic concerns). In such a case the positive function of strivings may not be noticeable. Our results replicate and broaden previous results which suggested that strong perfectionistic concerns are a crucial, negative force for the resolution of identity crises, as they contribute to higher anxiety and disorientation leading to a sense of being stuck in constant, unsuccessful attempts at establishing a satisfying form of identity. Perfectionistic concerns via lower self-esteem and more frequent feelings of shame make it difficult to reach a state where people feel that they found their place in the social world, since any situation that they find themselves in causes them to feel anxious and concerned, rather than content with self-realization. Our results mirror those obtained by Ashby et al. (2006), who showed that depression among female psychology students with high perfectionistic concerns can be traced back to frequent experience of shame and low self-esteem. This suggests that there might be a link between perfectionism, identity, and mental health that needs to be investigated further. Although the present study included a relatively small number of variables, it explained $33 \%$ of community identity variance. We may therefore suspect, that perfectionism and its cognitive-emotional correlates are an important source of individual differences in identity stage resolution.

To sum up, we suggest that the negative cognitiveemotional consequences of high perfectionistic concerns result in difficulties with identity formation by self-undermining identity-relevant decisions after they are made. As it was recently described by Van der Gaag and colleagues (2020), real life experiences which people have after they adopt a new identity determine whether the new identity commitments will be maintained or not. For people high in perfectionistic concerns, their everyday experiences are full of doubt, indecisiveness, feelings of shame and guilt which may be interpreted as 
'signs' that their identity decisions were not right. As a result, these feelings may undermine their commitments and make them relapse to a state of identity confusion. As perfectionism is a relatively stable trait (Rice \& Aldea, 2006) that starts developing early, usually during childhood (Morris \& Lomax, 2014), perfectionists may experience its strong negative impact that undermines their identity numerous times throughout their lifespan. This may lead to further difficulties, also those including mental health problems. Consequently, maladaptive perfectionistst may struggle with constant questions about their identity choices and this may lead to further difficulties, also those including mental health problems. This maladaptive process we describe here requires further verification in longitudinal studies.

\section{Practical Implications}

Our results have implications for clinical practice. While perfectionistic concerns may contribute to psychopathology (e.g. anxiety or affective disorders), they may also be subject to psychotherapeutic interventions (Handley et al., 2015). This is partly already done in numerous approaches to psychotherapy, for example in Schema Therapy (Young et al., 2003), where perfectionistic concerns may be considered an expression of unrelenting standards schema, accompanied by shame and guilt stemming from other schemas such as, for example, defectiveness. Other current approaches to therapy may also use the present study to address automatic thoughts and core beliefs facilitating perfectionistic concerns (methods used in Cognitive Behavioural Therapy; Beck, 2011), to strengthen engagement attached to perfectionistic strivings (one of the key elements of Acceptance and Commitment Therapy; Hayes et al., 2012) or to identify the mechanisms of influence of maladaptive motives on mental health via such emotions as shame and anxiety which is a core theme in Compassion Focused Therapy (Gilbert, 2020).

\section{Limitations}

This study addressed issues that have rarely been analysed and it provided new data on the potential mechanisms of identity development. However, its results must be considered with regard to its limitations. Firstly, this was a cross-sectional study, so the mediation model should be considered a proposal to be verified in future in longitudinal research. Secondly, the sample was small and it consisted mostly of women, which limits possible generalizations of the conclusions. Our results, although they are consistent with earlier research, must further be verified. However, it should be noted that despite a relatively small sample, the obtained results are highly convergent with other research on the perfectionism-identity link (Luyckx, Soenens, et al., 2008; Piotrowski, 2019), and on the factors that mediate the influence of perfectionism on adaptation (Ashby et al., 2006). We believe, that it supports our resuls as reliable and replicable.

Data Availability The data that support the findings of this study are openly available in the Open Science Framework repository at https:// osf.io/cn7hj/

Funding This research did not receive any specific grant from funding agencies in the public, commercial, or not-for-profit sectors.

\section{Declarations}

Ethical Approval All procedures performed in studies involving human participants were in accordance with the ethical standards of the institutional and/or national research committee (the Polish Code of Professional Ethics for the Psychologist; Polish Psychological.

Association) and with the 1964 Helsinki declaration and its later amendments or comparable ethical standards.

Informed Consent Informed consent was obtained from all individual participants included in the study.

Conflict of Interest The author(s) declared no potential conflicts of interest with respect to the research, authorship, and/or publication of this article.

Open Access This article is licensed under a Creative Commons Attribution 4.0 International License, which permits use, sharing, adaptation, distribution and reproduction in any medium or format, as long as you give appropriate credit to the original author(s) and the source, provide a link to the Creative Commons licence, and indicate if changes were made. The images or other third party material in this article are included in the article's Creative Commons licence, unless indicated otherwise in a credit line to the material. If material is not included in the article's Creative Commons licence and your intended use is not permitted by statutory regulation or exceeds the permitted use, you will need to obtain permission directly from the copyright holder. To view a copy of this licence, visit http://creativecommons.org/licenses/by/4.0/.

\section{References}

Ashby, J. S., Rice, K. G., \& Martin, J. L. (2006). Perfectionism, shame, and depressive symptoms. Journal of Counseling \& Development, $84,148-156$

Beck, J. S. (2011). Cognitive behavior therapy: Basics and beyond (2nd ed., pp. 19-20). New York: The Guilford Press.

Burnham, K. P., \& Anderson, D. R. (2004). Multimodel inference: Understanding AIC and BIC in model selection. Sociological Methods Research, 33, 261-304.

Castro, J., Soares, M. J., Pereira, A., \& Macedo, A. (2017). Perfectionism and negative/positive affect associations: The role of cognitive emotion regulation and perceived distress/coping. Trends in Psychiatry and Psychotherapy, 39, 77-87.

Chen, F. F. (2007). Sensitivity of goodness of fit indexes to lack of measurement invariance. Structural Equation Modeling, 14, 464504.

Côté, J. E. (1996). Sociological perspective in identity formation: The culture-identity link and identity capital. Journal of Adolescence, $19,417-428$. 
Côté, J. E. (1997). An empirical test of the identity capital model. Journal of Adolescence, 20, 577-597.

Côté, J. E. (2006). Emerging adulthood as an institutionalized moratorium: Risks and benefits to identity formation. In J. J. Arnett \& J. L. Tanner (Eds.), Emerging adults in America: Coming of age in the 21st century (pp. 85-116). Washington, DC: American Psychological Association.

Côté, J. E. (2016). The identity capital model: A handbook of theory, methods, and findings. Unpublished manuscript. London: Department of Sociology, The University of Western Ontario.

Crocetti, E., Rubini, M., \& Meeus, W. (2008). Capturing the dynamics of identity formation in various ethnic groups: Development and validation of a three-dimensional model. Journal of Adolescence, 31, 207-222.

Curran, T., \& Hill, A. P. (2019). Perfectionism is increasing over time: A meta-analysis of birth cohort differences from 1989 to 2016. Psychological Bulletin, 14, 410-429.

Dimaggio, G., Lysaker, P. H., Calarco, T., Pedone, R., Marsigli, N., Riccardi, I., Sabatelli, B., Carcione, A., \& Paviglianiti, A. (2015). Perfectionism and personality disorders as predictors of symptoms and interpersonal problems. American Journal of Psychotherapy, 69, 317-330

Enns, M., Cox, B., \& Clara, I. (2002). Adaptive and maladaptive perfectionism: Developmental origins and association with depression proneness. Personality and Individual Differences, 33, 921-935.

Erikson, E. H. (1950). Childhood and society. New York: Norton \& Co..

Eum, K., \& Rice, K. G. (2011). Test anxiety, perfectionism, goal orientation, and academic performance. Anxiety, Stress, and Coping, 24, 167-178.

Flett, G. L., Madorsky, D., Hewitt, P. L., \& Heisel, M. J. (2002). Perfectionism cognitions, rumination, and psychological distress. Journal of Rational-Emotive \& Cognitive-Behavior Therapy, 20, 33-47.

Flett, G. L., Nepon, T., \& Hewitt, P. L. (2016). Perfectionism, worry, and rumination in health and mental health: A review and a conceptual framework for a cognitive theory of perfectionism. In W. F. M. Sirois \& D. S. Molnar (Eds.), Perfectionism, health, and well-being (pp. 121-155). New York: Springer.

Frost, R. O., Marten, P., Lahart, C., \& Rosenblate, R. (1990). The dimensions of perfectionism. Cognitive Therapy and Research, 14, 449468.

Gilbert, P. (2020). Compassion: From its evolution to a psychotherapy. Frontiers in Psychology, 11, 1-31.

Handley, A. K., Egan, S. J., Kane, R. T., \& Rees, C. S. (2015). A randomised controlled trial of group cognitive behavioural therapy for perfectionism. Behaviour Research and Therapy, 68, 37-47.

Harder, D. H., \& Zalma, A. (1990). Two promising shame and guilt scales: A construct validity comparison. Journal of Personality Assessment, 55, 729-745.

Hayes, S. C., Strosahl, K. D., \& Wilson, K. G. (2012). Acceptance and commitment therapy: The process and practice of mindful change (2nd ed.). New York: Guilford Press.

Hewitt, P. L., \& Flett, G. L. (1991). Perfectionism in the self and social contexts: Conceptualization, assessment, and association with psychopathology. Journal of Personality and Social Psychology, 60, 456-470.

Holmbeck, G. N. (1997). Toward terminological, conceptual, and statistical clarity in the study of mediators and moderators: Examples from the child-clinical and pediatric psychology literatures. Journal of Consulting and Clinical Psychology, 65, 599-610.

Hu, L., \& Bentler, P. (1999). Cutoff criteria for fit indices in covariance structure analysis: Conventional criteria versus new alternatives. Structural Equation Modeling, 6, 1-55.

Klimstra, T. A., \& Denissen, J. J. A. (2017). A theoretical framework for the associations between identity and psychopathology. Developmental Psychology, 53, 2052-2065.
Łaguna, M., Lachowicz-Tabaczek, K., \& Dzwonkowska, I. (2007). Skala Samooceny SES Morrisa Rosenberga - polska adaptacja metody. Psychologia Spoleczna, 2, 164-176.

Lewis, M. (2008). Self-conscious emotions: Embarrassment, pride, shame, and guilt. In M. Lewis, J. M. Haviland-Jones, \& L. F. Barrett (Eds.), Handbook of emotions (pp. 742-756). New York: The Guilford Press.

Luyckx, K., Schwartz, S. J., Berzonsky, M. D., Soenens, B., Vansteenkiste, M., Smits, I., \& Goossens, L. (2008). Capturing ruminative exploration: Extending the four-dimensional model of identity formation in late adolescence. Journal of Research in Personality, 42, 58-82.

Luyckx, K., Soenens, B., Goossens, L., Beckx, K., \& Wouters, S. (2008). Identity exploration and commitment in late adolescence: Correlates of perfectionism and mediating mechanisms on the pathway to well-being. Journal of Social and Clinical Psychology, 27, 336361.

Malivoire, B., Kuo, J., \& Antony, M. (2019). An examination of emotion dysregulation in maladaptive perfectionism. Clinical Psychology Review, 71, 39-50.

Marcia, J. E. (1980). Identity in adolescence. In J. Adelson (Ed.), Handbook of adolescent psychology (pp. 159-187). New York: Wiley.

Morris, L., \& Lomax, C. (2014). Review: Assessment, development, and treatment of childhood perfectionism: A systematic review. Child and Adolescent Mental Health, 19, 225-234.

Muthén, L. K. \& Muthén, B. O. (1998-2012). Mplus user's guide. Seventh Edition. Los Angeles, CA: Muthén \& Muthén.

Orth, U., Berking, M., \& Burkhardt, S. (2006). Self-conscious emotions and depression: Rumination explains why shame, but not guilt, is maladaptive. Personality and Social Psychology Bulletin, 32, 16081619.

Piotrowski, K. (2019). Perfectionism and identity processes in two domains: Mediational roles of worry, rumination, indecisiveness, shame, and guilt. Frontiers in Psychology, 10(1864), 1-11.

Piotrowski, K. (2020). How good it would be to turn back time: Adult attachment and perfectionism in mothers and their relationships with the processes of parental identity formation. Psychologica Belgica, $60,55-72$.

Piotrowski, K. \& Bojanowska, A. (2019). Factor structure and psychometric properties of a polish adaptation of the frost multidimensional perfectionism scale. Current Psychology. Online first.

Piotrowski, K., \& Brzezińska, A. I. (2015). Polska adaptacja kwestionariusza identity stage resolution index (ISRI) Jamesa Côté. Studia Psychologiczne, 53, 33-45.

Piotrowski, K., \& Brzezińska, A. I. (2017). Skala Wymiarów Rozwoju Tożsamości DIDS: Wersja zrewidowana. Psychologia rozwojowa, 4, 89-111.

Reuther, E., Davis, T., Rudy, B., Jenkins, W., Whiting, S., \& May, A. (2013). Intolerance of uncertainty as a mediator of the relationship between perfectionism and obsessive-compulsive symptom severity. Depression and Anxiety, 30, 773-777.

Rice, K. G., \& Aldea, M. A. (2006). State dependence and trait stability of perfectionism: A short-term longitudinal study. Journal of Counseling Psychology, 53, 205-213.

Rosenberg, M. (1965). Society and the adolescent self-image. New York: Princeton University Press.

Satorra, A., \& Bentler, P. M. (1994). Corrections to test statistics and standard errors in covariance structure analysis. In A. von Eye \& C. C. Clogg (Eds.), Latent variables analysis: Applications for developmental research (pp. 399-419). Thousand Oaks: Sage Publications.

Sirois, F., \& Molnar, D. (2014). Perfectionism and maladaptive coping styles in patients with chronic fatigue syndrome, irritable bowel syndrome and fibromyalgia/arthritis and in healthy controls. Psychotherapy and Psychosomatics, 83, 384-385. 
Slof-Op't, L., Claes, L., \& van Furth, E. (2016). Classifying eating disorders based on "healthy" and "unhealthy" perfectionism and impulsivity. International Journal of Eating Disorder, 49, 673-680.

Stoeber, J., \& Damian, L. E. (2016). Perfectionism in employees: Work engagement, workaholism, and burnout. In F. M. Sirois \& D. S. Molnar (Eds.), Perfectionism, health, and well-being (pp. 265284). New York: Springer.

Stoeber, J., \& Otto, K. (2006). Positive conceptions of perfectionism: Approaches, evidence, challenges. Personality and Social Psychology Review, 10, 295-319.

Stoeber, J., Corr, P. J., Smith, M. M., \& Saklofske, D. H. (2018). Perfectionism and personality. In J. Stoeber (Ed.), The psychology of perfectionism: Theory, research, applications (pp. 68-88). London: Routledge.
Ulu, I., \& Tezer, E. (2010). Adaptive and maladaptive perfectionism, adult attachment, and big five personality traits. Journal of Psychology, 144, 327-340.

Van der Gaag, M. A. E., De Ruiter, N. M. P., Kunnen, S. E., \& Bosma, H. (2020). The Landscape of Identity Model: An integration of qualitative and quantitative aspects of identity development. Identity, 20, $272-289$.

Young, J. E., Klosko, J. S., \& Weishaar, M. E. (2003). Schema therapy: A practitioner's guide. New York: Guilford Press.

Publisher's Note Springer Nature remains neutral with regard to jurisdictional claims in published maps and institutional affiliations. 